\title{
LIGHTWAND \& GLIDESCOPE VS. MACINTOSH FOR POTENTIAL C-SPINE INJURY
}

Timothy P. Turkstra, M. Eng. MD, Rosemary A. Craen, MB BS, David M. Pelz, MD, Adrian W. Gelb, MB ChB

Depts Anesthesia \& Radiology, University of Western Ontario, 339 Windermere Rd, London, N6A 5A5

INTRODUCTION: The optimum technique for intubation of a patient who may have a cervical spine (C-spine) injury remains unresolved $(1,2)$. Using fluoroscopic video, we compared C-spine

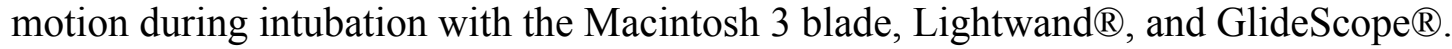

METHODS: Following IRB approval, 47 healthy patients consented and were randomized to participate in a crossover trial of Macintosh laryngoscopy versus either Lightwand (Intubating Lighted Stylet) or GlideScope use. In-line stabilization was provided. We examined C-spine motion during laryngoscopy at four areas: the Occiput-C1 junction, $\mathrm{C} 1-\mathrm{C} 2$ junction, $\mathrm{C} 2-\mathrm{C} 5$ motion segment, and $\mathrm{C} 5$-Thoracic motion segment. Time required to intubate was also measured.

RESULTS: C-spine motion using the Lightwand averaged 57\% less than that during Macintosh laryngoscopy at the 4 motion segments studied, $\mathrm{p}<0.03$ at each segment. (Figure) There was no difference in time to intubate between Lightwand (14 $\pm 9 \mathrm{~s})$ and Macintosh (16 $\pm 8 \mathrm{~s})$ use.

$\mathrm{C}$-spine motion was reduced by $50 \%$ at the $\mathrm{C} 2-\mathrm{C} 5$ motion segment for GlideScope versus Macintosh use, $\mathrm{p}<0.04$. There were no significant differences at the other segments. (Figure) Use of the GlideScope (26 \pm 12 s) took $60 \%$ longer than Macintosh blade, $p<0.01$.

DISCUSSION: For patients in whom cervical spine movement is undesirable, use of the Lightwand by an experienced user may be advantageous.

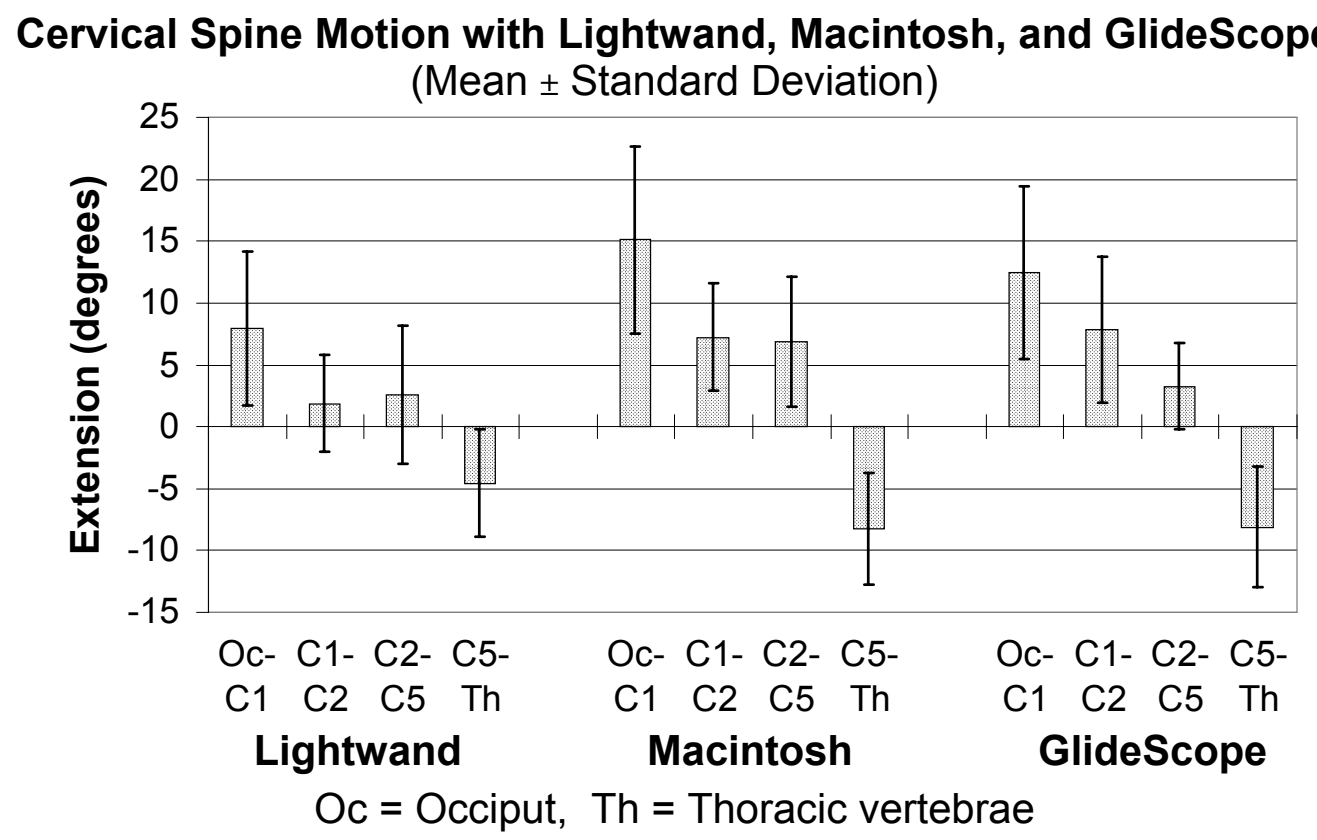

\section{REFERENCES:}

1. Can J Anesth 2002, 49:7, 733-44

2. Advanced Trauma Life Support for Doctors, ATLS Student Course Manual, $7^{\text {th }}$ Ed. Ch $1,2,7$.

3. Funding acknowledged: 2004 CAS Resident Research Grant, unrestricted. 